\title{
The Effects of Team Training on Team Outcomes: A Meta-Analysis
}

\author{
Lisa A. Delise, C. Allen Gorman, PhD, Abby M. Brooks, PhD, Joan R. Rentsch, \\ $P h D$, and Debra Steele-Johnson, PhD
}

$\mathrm{R}$ esearch on individual-level training has made great strides toward sound theories and methand examples, see Ford, Kozlowski, Kraiger, Salas, \& Teachout, 1997; Goldstein \& Ford, 2002). Training researchers have attended to reviewers' suggestions for improving training as a field and, as a result, have focused their research on improving needs analysis, defining training objectives, developing effective sequencing of training events, and advancing new methods and theoretical frameworks (Campbell, 1971; Ford, 1997; Tannenbaum \& Yukl, 1992). Although attention and effort directed toward improving the rigor of individual-level training research have increased, research on training at the team level of analysis has not been examined as extensively or as rigorously.

A team is defined as at least two people who interact with one another in an interdependent and adaptive manner to reach a common goal (Salas, Dickinson, Converse, \& Tannenbaum, 1992). Examples of teams include top management teams, task forces, and surgical teams. Since the mid-1980s, team training (a planned effort administered in a team environment to improve team performance; Goldstein \& Ford, 2002) in organizations has become more prevalent due to the need for organizations to address integration across departments and functions (Ilgen, 1999) and the visibility of teams such as flight crews and air traffic controllers (Stout, Salas, \& Fowlkes, 1997). The need to understand and improve team performance (the outputs and outcomes a team generates, such as products or services, individual satisfaction, and team viability (Hackman, 1987) increases as organizations tackle multifaceted issues and the need for collaboration and high-quality team performance grows (O'Connor \& Yoon, 2008). A 2008 survey administered by the American Society for Training and Development indicated that organizations spent $\$ 134$ billion

PERF ORM A N C E I M PROVEMENT Q UARTERLY, 22 ( 4) P P. 53 - 80

(C) 2010 International Society for Performance Improvement

Published online in Wiley InterScience (www.interscience.wiley.com). DOI: 10.1002/piq.20068 
on training, learning, and development, suggesting that team training is indeed an important avenue for research (Paradise, 2008). In team-based work environments, team members must possess the knowledge, skills, and abilities (KSAs) that enable them to communicate and coordinate with team members and perform complex tasks that require smooth integration of each team members' competencies. Team members are expected not only to possess these KSAs, but often to perform them effectively in stressful situations (Cannon-Bowers \& Salas, 1997; Volpe, Cannon-Bowers, Salas, $\&$ Spector, 1996), such as under time pressure, in distributed team environments, and facing information overload or deficiencies. Thus, as the use of teams in organizations increases and as the performance requirements of team members become progressively more complex, effective team training is becoming an organizational necessity (Paris, Salas, \& Cannon-Bowers, 2000; Stout et al., 1997). Systematic and formal team training is expected to develop a team's ability to achieve high performance (Goldstein \& Ford, 2002).

Recently research on team training has accumulated enough data to enable an empirical examination of the effects of team training on team outcomes. Team training research has been conducted in the laboratory and in a variety of organizations (e.g., hospitals, underground silver mines, military command teams, military combat corps, and military academies) with ad hoc teams designed for the purpose of research and intact teams actively participating in organizational life. Although the studies included in the meta-analysis in this article span over 20 years (1986-2007), no quantitative analysis has been conducted to determine what is known about the relationship between team training and team outcomes. Previous literature reviews have provided qualitative analyses of the team training literature, but those analyses (many of which included different studies) have unearthed only weak support for the effectiveness of team training on outcomes (Stout et al., 1997). In addition, the Kraiger, Ford, and Salas (1993) framework for learning outcomes, discussed in detail here, is now available to evaluate not only the overall effects of training but also its effects on specific outcome types. At this point in the development of the literature, an evaluation of training research at the team level of analysis is needed to guide future research efforts. Therefore, the purpose of the study presented here is to summarize and evaluate the research on team-level training using meta-analysis to determine its effects on team-level outcomes.

\section{Team Training}

The focus in this research is team training, which differs from teambuilding interventions (Tannenbaum, Beard, \& Salas, 1992). Almost a decade ago, Salas, Rozell, Mullen, and Driskell (1999) conducted a meta-analysis of the effects of team-building components (goal setting, interpersonal relations, problem solving, and role clarification) on team performance. How- 
ever, the meta-analysis here focuses on team training rather than on team building or individual training. Team training is defined as a planned effort designed to improve team performance (Baldwin \& Magjuka, 1997; Goldstein \& Ford, 2002) by assisting individuals in the acquisition of new information, skills, and attitudes essential to effective performance in a team environment (Colquitt, LePine, \& Noe, 2000; Goldstein \& Ford, 2002). In contrast, team-building interventions do not target skills related specifically to the immediate team task. Rather, they focus on problem solving and interpersonal issues (Klein et al., 2009) such as conflict management, trust building, or decision-making skills.

With respect to team effectiveness, which is the degree of success of a team's performance, individual training is important to ensure team members are equipped with the knowledge, skills, and abilities necessary to complete their portions of team tasks (Buller \& Bell, 1986; Wang, 1994). However, because each member of a team typically performs unique roles that must be integrated with other members' roles in order to accomplish team tasks and goals (Goldstein \& Ford, 2002), individual-level team member competency is necessary but not sufficient for effective team performance. That is, team members must develop teamwork KSAs that include understanding the roles performed by each member of the team, the interdependencies among these roles, and the means for integrating the roles. For a team to work effectively, teamwork skills must be implemented in addition to the requisite individual skills.

Team training is a specific type of training administered to an entire team, aimed at enhancing the performance of the team as a unit. It is a planned effort to develop a team's task-specific competencies, thereby improving its ability to perform its tasks effectively. The impact of team training on team effectiveness has not been thoroughly examined in the training literature. Thus, our study supplements previous research by evaluating the effects of team training on team outcomes. Consistent with the goal of team training, the criterion variables we examined were measures of team outcome effectiveness at the team level of analysis (either collectively or holistically measured). Because the objective of team training is to improve the performance of a team as a unit that requires coordination among its members, the examination of team effectiveness outcomes requires more than a simple aggregate of individual KSAs.

In this study, team effectiveness was evaluated by extending Kraiger, Ford, and Salas's (1993) model of training outcomes to the team level of analysis. Kraiger et al. delineated a construct-oriented classification system of individual learning outcomes that can be used as a theoretical basis for individual training evaluation. Because they view learning outcomes as multidimensional, individual learning should be evidenced by changes in affective, cognitive, and skill-based outcomes. Recently the model has been applied to the evaluation of team training (Ellis, Bell, Ployhart, Hollenbeck, \& Ilgen, 2005; Rapp \& Mathieu, 2007), indicating that learning in teams as a result of team training may also be evidenced by changes in team-level affective, cognitive, and skill-based outcomes. The classifications used in the 
original model were employed with several extensions relevant to examining team training outcomes. In particular, the extensions included the addition of a teamwork skills outcome classification and the expansion of the skillbased outcomes into two categories for subjectively and objectively measured skills.

Consistent with the original model, teams can exhibit affective, cognitive, and task-based skill outcomes in response to training, whether these outcomes are initially measured at the team level or whether individual assessments are aggregated to the team level of analysis. We extended the model to more completely assess team effectiveness by including a teamwork skill outcome. Work in teams involves complex interpersonal competencies (teamwork skills), including high-level communication and coordination skills that are sometimes targets of team training. Teamwork skills are the focus of much research in the literature on teams and can be viewed not only as the mechanisms through which teams perform their work and effectively produce other outcomes but also as outcomes in and of themselves. In sum, when team training is evaluated, an additional outcome category should be evaluated to capture the unique role that teamwork skills play in team interactions.

Kraiger et al. (1993) identified skills as a broad outcome category. In the case of team training at the team level of analysis, task-based outcomes are typically evaluated using team-level skill outcomes associated with the task (e.g., assembly errors, combat readiness). However, we distinguished between team-level task-based skill outcomes that are measured objectively and those that are measured subjectively by subject matter experts or by the team itself. Previous work on performance appraisal methods indicated that the estimated average correlation between subjective and objective measures is only .39 (Bommer, Johnson, Rich, Podsakoff, \& MacKenzie, 1995), suggesting that subjective and objective measures are related but are not interchangeable. Because they likely capture different aspects of task-based skill, subjective and objective measures of task-based skill outcomes are often evaluated in a single study. Thus, the criterion framework used in this study distinguishes between subjectively and objectively measured outcomes. No similar distinctions were made for affective, cognitive, and teamwork skill outcomes because of the types of measurements used in each of these categories.

\section{Hypotheses}

The literature on team training reveals that some empirical team training studies have focused on developing team members' cognitive frameworks and schemas necessary for a similar understanding of task and teamwork requirements. Other team training has focused on teaching individual-level behavioral skills that should be reflected in effective performance on subjective and objective task-based skill outcome measures at the team level. Many team training articles have focused on training teamwork skills, including communication and coordination, which are necessary for successful integration of team member contributions and high-quality team 
performance. In addition to the overall enhancement of team effectiveness, team training has also focused specifically on increasing advancement in each of the outcome categories. Therefore, we present two hypotheses regarding the effectiveness of team training:

Hypothesis 1. Team training will have a positive effect on overall team effectiveness.

Hypothesis 2. Team training will have a positive effect on each of the five aspects of team effectiveness: affective, cognitive, subjective task-based skill, objective task-based skill, and teamwork skill.

\section{Moderator Variable Hypotheses}

A number of variables have emerged in the literature as potential moderators of team effectiveness: job type, job level, team experience, training content, delivery method, training task, reinforcement for training performance, and climate for training. The small number of empirical studies that provide information about most of these variables precludes moderator analyses. However, enough data exist to examine five potential moderators of theoretical interest to the team training literature: sample type, research setting, team status, evaluation setting, and study design. Therefore, the associated hypotheses were evaluated.

Sample Type. Team training studies have been conducted using civilian and military samples, and there is reason to believe that findings from military environments may be generalized to civilian organizational settings (Cannon-Bowers \& Salas, 1998), although there may be differences between the military samples and the civilian samples. For example, team structure is theorized to have an effect on how team members work together (e.g., Sundstrom, DeMeuse, \& Futrell, 1990). From this perspective, military teams typically have a well-defined structure in which leaders are appointed and member status is salient. Although civilian teams may also have appointed leaders, civilian leaders may more likely be elected or emergent within the team. In addition, although there may be status differences between leaders and members of civilian teams, those differences may be less formal and potentially less explicit than in military teams. These factors may result in differences in team effectiveness across sample type.

Another potential difference between the sample types is that military participants are likely to have had extensive experience with structured, well-designed, stringently implemented training programs. All military personnel receive basic training at the beginning of their military careers and training for their particular jobs to ensure competency in their task requirements. However, in many civilian organizations, training may be less formal, such as on-the-job training, which, according to Carnevale and Gainer (1989), is the most commonly used organizational training method, and civilians in general may not have as much exposure to extensive, structured training programs. Because differences between these two sample types may 
have differential effects on training effectiveness, we evaluated the following hypothesis:

Hypothesis 3. Sample type will moderate the relationship between team training and team effectiveness, including each of the five aspects of team effectiveness.

Research Setting. Hackman (1987) indicated that carefully designed and implemented lab studies can generate powerful tests of conceptual propositions. This is particularly relevant when researchers are initiating the study of new or previously unstudied phenomena. Given that the research on team training is only now beginning to accumulate and is often focused on basic research questions, the control of laboratory studies has much to offer. Indeed, lab settings typically afford more control over the environment and the amount and type of interaction to which team members are exposed than do field studies. Thus, researchers examining basic questions in team training (such as how to train teamwork skills or how cognitive training can be integrated with task-based skill training to facilitate training outcomes) may benefit from the use of lab studies.

This control, however, can also be viewed as a limitation of lab studies. Indeed, the contrived nature of many lab studies calls into question the realism of the situation for participants. When lab tasks do not accurately mirror reality, teams may be less motivated to perform well and team members may interact differently than they would in realistic and personally salient team settings. Also, in terms of realism, field studies allow investigation of teams operating within an organizational culture that can shape many aspects of a team's environment, attitude, motivation, and expectations. In these situations, field studies may more accurately capture how teams perform in their natural settings-settings in which the everyday lives of the members revolve around interactions with their team members and performance of the team. Given the unique attributes of lab and field studies, we expect to find differences in team training outcomes between teams trained in lab and field settings. Therefore, we present the following hypothesis:

Hypothesis 4. Research setting will moderate the relationship between team training and team effectiveness, including each of the five aspects of team effectiveness.

Team Status. Team status has been presented in the team literature as an important moderator of team performance. Bushe and Coetzer (1995) indicated that although team training is most important for teams that are ongoing and intact, even short-term teams need basic skills for success. Ad hoc teams provide a convenient opportunity to study initial team behaviors and investigate how real-life short-term teams may behave. Members of intact teams with a history of working together not only have in-depth 
knowledge of the task and teamwork capabilities of their teammates but also are aware of how they work together on a particular task. Also, members of intact teams may have stronger affective bonds than members of ad hoc teams. Long-standing positive or negative affect between team members can influence how well or how poorly they work together on a task (Barrick, Stewart, Neubert, \& Mount, 1998; Bettenhausen, 1991; Mullen \& Copper, 1994; Zaccaro \& McCoy, 1988). However, because members of ad hoc teams may lack understanding of each other's KSAs, they may not have an adequate basis to trust one another and may have difficulty learning to rely on one another during team training episodes. Ad hoc and intact teams are likely to differ in terms of reactions to and outcomes of team training. Therefore, we present the following hypothesis:

Hypothesis 5. Team status will moderate the relationship between team training and team effectiveness, including each of the five aspects of team effectiveness.

Evaluation Setting. Training effectiveness is traditionally measured at two points in the learning process. First, trainees are tested immediately after training to determine whether training objectives have been met. Second, trainees are sometimes evaluated on the job, at some point after training, to determine whether they are transferring the principles and KSAs they learned in training to the work environment. Goldstein and Ford (2002) indicated that if trainees cannot learn and retain KSAs immediately after training, the expectation of transfer to the work environment is futile. However, although learning in training is a prerequisite for transfer, learning during training is not sufficient to ensure effective transfer into the work environment. Several factors can affect the degree of transfer into the job setting. Goldstein and Ford (2002) indicated that specific desired behaviors and the settings in which they should be performed must be delineated so it will be clear whether training should focus on teaching exact skills that will be used on the job or on teaching skills that will need to be generalized and adapted in the work environment. If training does not also provide instruction on methods for adaptation, this may have a negative effect on the degree to which skills will transfer into appropriate behaviors on the job.

Goldstein and Ford (2002) also indicated that training should take into account how long the KSAs learned in a training episode will need to be maintained and the factors within the job and organization that can help to develop and maintain those KSAs. If attention is not paid to maintenance, opportunity to perform, and motivation, transfer evaluations may not reflect the skills learned in training. They suggested that because training is a social situation, it can be affected by social constraints. Rouillier and Goldstein (1993) discussed transfer climate as important to facilitating skill transfer on the job, specifically situational cues and consequences of training. Baldwin and Magjuka (1997) suggested that management support (including supervisor commitment and involvement) and organizational support (including organizational incentives) are key to 
developing a helpful environment in which transfer can effectively occur. In addition, the job itself can motivate trainees to transfer their new skills into the work environment. Ford, Quiñones, Sego, and Sorra (1992) found that trainees often had differential opportunities to perform newly learned skills. When trainees have opportunities to practice their skills, they may perform better in transfer tasks than those without the opportunities to practice. Given the potential for aspects of training environments and trainee motivations to affect measures taken in the transfer environment, we expect there may be differences in the strength of the relationship between team training and effectiveness outcomes for those measured immediately after training and those measured later in the transfer environment. Therefore, we present the following hypothesis:

Hypothesis 6. Evaluation setting will moderate the relationship between team training and team effectiveness, including each of the five aspects of team effectiveness.

Study Design. Goldstein and Ford (2002) discussed the advantages and disadvantages of a variety of research designs for determining effectiveness of training on measured outcomes. For example, although using a pretest/ posttest method of assessment can indicate whether changes have occurred in the measured outcomes from before the training to after it, there are limitations to the inferences that can be made. It is not possible to determine a causal relationship between training interventions and the changes in relevant outcome variables because those designs do not allow random assignment of individuals to conditions. Another limitation is that these designs do not account for changes that may happen simply due to the passage of time, events external to the training intervention, or the placebo effects of training. Conversely, between-subjects designs with random assignment of participants to control and experimental conditions allow the experimenter to determine if the training intervention was the most influential factor for outcome changes during the study. Designs that use a crossed-, between-, and within-subjects design (pretest/posttest measures with control/ experimental groups) also control for these extraneous variables that could affect performance on measures given after training episodes. Because study designs with mechanisms for comparison between control and experimental groups are more rigorous in this way, it may be possible to find larger effects in these types of studies than in studies that made use of only a pretest/posttest design. Therefore, we present the following hypothesis:

Hypothesis 7. Study design will moderate the relationship between team training and team effectiveness, including each of the five aspects of team effectiveness.

\section{Meta-Analysis}

The methodology used for our study is meta-analysis, which provides a quantitative summary of the literature on a topic. This methodology, 
explicated by Hunter and Schmidt (1990), allows researchers to understand relationships among variables by examining the empirical relationships found between those variables across studies reported in the literature. Statistics (such as correlation coefficients, $t$-values, or $F$-values) are extracted from each individual study and used to create a data set that is analyzed by meta-analytic techniques to describe the variability in and magnitude of the relationships between variables. In contrast to qualitative summary methods, such as narrative literature reviews, meta-analysis provides a more objective evaluation of a body of quantitative literature because it is subject to fewer of the personal biases that may be applied when evaluating research in a qualitative

In contrast to qualitative summary methods, such as narrative literature reviews, meta-analysis provides a more objective evaluation of a body of quantitative literature. manner.

\section{Method}

\section{Literature Search}

A literature review was conducted in relevant online databases (PsycINFO, Business Source Premier) for published, empirical work using the search terms training and development and teams, teams and training, team training, team development, group training, military training and teams, and team building. Because our study was a meta-analysis, only empirical quantitative work could be used as input for the statistical analyses. This search generated 374 abstracts for initial perusal. In addition, a manual search of team training review articles was conducted. Inspection of the abstracts revealed that the large majority of them did not have team training as their focus. Rather, they included references to training and teams or groups but did not feature research specifically addressing the training of teams. After eliminating those abstracts, 56 articles with abstracts that seemed to point to an instance of team training remained for evaluation. After closer inspection determined that 7 of those were not quantitative articles, 5 did not include training, and 10 did not use a team criterion (i.e., they were not collected at the team level and did not provide enough information to aggregate to the team level), they were removed from the potential list for coding. The first three authors each reviewed two thirds of the abstracts and articles such that each third was reviewed by two raters. They initially agreed on the inclusion status of $86 \%$ of the articles. When there was disagreement, the two raters discussed the article and decided whether to retain or reject it based on consensus.

\section{Selection and Coding of the Studies}

The three raters reviewed a portion of the remaining 34 articles to determine which were appropriate for inclusion in the meta-analysis. Each article was reviewed independently by two raters. Four additional studies were removed from the sample because all team members were not trained ( 2 
articles) or they were case studies of a single team ( 2 articles). This method yielded 31 possible articles to be coded for the meta-analysis.

In order to be included in the analysis, studies had to meet the following criteria: used a team-level criterion variable, reported the number of teams in the sample, and reported appropriate statistics at the team level for conversion to effect sizes. By these criteria, 22 articles (23 studies) were identified for inclusion in this meta-analysis. All of these articles were published in peerreviewed, refereed journals. (These articles are indicated in the References section with an asterisk.) Numerical information coded for each study included the number of teams, number of team members on each team, appropriate statistical findings for meta-analysis (such as means, correlations, $F$-values, and variance measures), reliability estimates of predictor and criterion measures, and demographic information. The first two authors coded each of the studies for moderator variables and, in cases where they did not agree, discussed their coding until consensus was reached.

\section{Statistical Procedures}

In order to carry out the most conservative meta-analysis, a bare-bones meta-analysis was conducted (Allen, Eby, Poteet, Lentz, \& Lima, 2004). A bare-bones meta-analysis is conservative because it includes no corrections for artifacts in the data beyond sampling error as additional corrections can provide inaccurate results from the analyses when using a small sample of studies (Spector \& Levine, 1987). Because our study included only published, refereed studies, we constructed a funnel plot using each effect size and its associated sample size to determine whether the sample we used was subject to publication bias. Publication bias may exist when studies with positive effects are published more often than studies with negative or nonsignificant effects. In a meta-analysis, publication bias can affect the results by limiting the analyzed data to studies with positive findings and excluding data that present opposite findings. Therefore, testing for publication bias allows researchers to determine if bias exists in a pool of published studies whose effect sizes are used as input data for the meta-analysis. Researchers can test for publication bias using a funnel plot. A plot in the shape of an inverted funnel (where there is more variance in effect sizes for studies with smaller samples but less variance in effect sizes for studies with larger samples) would indicate low levels of publication bias (Hunter \& Schmidt, 2004).

After coding all of the studies, summary statistics were computed using Meta-Analyzer 5.2, an Excel-based meta-analysis program developed by Aamodt (2005). The formulas used in Meta-Analyzer 5.2 have been validated (Aamodt \& Custer, 2006) using data sets and meta-analytic results from Arthur, Bennett, and Huffcutt (2001) and Hunter and Schmidt (1990).

Effect sizes were calculated for each hypothesis test in each study and were converted to effect sizes $(d s)$ using the formulas provided by Arthur et al. (2001). In this method of meta-analysis, multiple effect sizes obtained from a single study were averaged into a single effect size for each training outcome. This process resulted in 41 effect sizes to be analyzed in our study. 


\section{Team Effectiveness Measures}

Next, criterion variables were grouped into the five team training outcomes: affective outcomes, cognitive outcomes, subjective task-based skill outcomes, objective task-based skill outcomes, and teamwork skill outcomes. Effect sizes were computed for the overall sample and for each of the five outcome categories. Each outcome was initially assessed at the team level or based on a team level aggregate:

- Affective outcomes. Ten measures from six studies were categorized as affective outcomes that indicated feelings and beliefs regarding the team as a whole, the team leaders, or the members' personal gain from the training. Examples of measures of affective outcomes are personal benefits of training (Ibbetson \& Newell, 1996), ratings of affect toward the group leader (Polley \& Eid, 1990), collective efficacy (Brown, 2003), and group efficacy (Gibson, 2001).

- Cognitive outcomes. Seven measures from four studies were categorized as cognitive outcomes that indicate some type of cognitive change attained by the trainees. Example cognitive measures are ratings of interpositional knowledge (knowledge an individual holds with respect to the roles and needs of other team members under the demands of specific task situations; Cannon-Bowers, Salas, Blickensderfer, \& Bowers, 1998), development of shared mental models (Marks, Sabella, Burke, \& Zaccaro, 2002), and procedural recall and memory differentiation (Liang, Moreland, \& Argote, 1995).

- Subjective task-based skill outcomes. Six measures from four studies were categorized as subjective task-based skill outcomes that were based on team member and subject matter expert perceptions of performance. Example measures are team performance (as indicated by expert ratings on a BARS scale; Entin \& Serfaty, 1999), team effectiveness (Ibbetson \& Newell, 1996), technical competency (Volpe et al., 1996), and combat readiness (Bottger \& Yetton, 1987).

- Objective task-based skill outcomes. Twenty measures from nine studies were categorized as objective task-based skill outcomes. Examples of objective measures are team performance (as indicated by points earned in a simulation game; Day et al., 2005), tons per manshift (Buller, 1988; Buller \& Bell, 1986), accuracy and speed (Cannon-Bowers et al., 1998), and assembly errors and assembly time (Liang et al., 1995).

- Teamwork skill outcomes. Thirty-two measures from eight studies were categorized as teamwork skill outcomes. These consisted of measures that described how team members worked together, communicated, and coordinated. Examples are volunteering information and process quality (Cannon-Bowers et al., 1998), positive and negative verbal and nonverbal communication (Kaiser, Hahlweg, Fehm, \& Groth, 1998), agreements and acknowledgments (Volpe et al., 1996), conflict handling (Bottger \& Yetton, 1987), and leadership and coordination (Eden, 1985). 


\section{Moderator Variables}

Variables appropriate for moderator analysis were identified based on their theoretical interest to the team training literature. Sample type was coded as either civilian or military (the latter included student cadets and professional military personnel). Research setting was coded as either laboratory or field, which could easily be discerned for all studies based on the descriptions provided in the method sections. Team status was coded as either ad hoc or intact. This variable was coded for studies in which the authors indicated team status. Evaluation setting was coded as training or transfer based on whether the outcomes were measured immediately after training in the training setting or measured later (after training) in an applied setting. Study design was coded as between subjects when the design included experimental and control groups, as within-subjects when the design included pre- and posttest measures for the same subject, or crossed when the design included a mix of between and within assessments.

\section{Results}

The results of the meta-analysis are shown in Table 1 . Hypothesis 1 predicted that team training would have a positive relationship with team effectiveness. Overall, team training was found to be related to team outcomes $(d=.85)$. Thus, hypothesis 1 was supported. Hypothesis 2 predicted that team training would be positively related to each of the five categories of team effectiveness. Results indicated that hypothesis 2 was supported because team training was positively related to affective outcomes $(d=.80)$, cognitive outcomes $(d=1.37)$, subjective task-based skill outcomes $(d=.88)$, objective task-based skill outcomes $(d=.76)$, and teamwork skill outcomes $(d=.64)$. Despite the differences in the effect size values,

\begin{tabular}{|c|c|c|c|c|c|c|}
\hline TEAM TRAINING OUTCOME & $\boldsymbol{k}$ & $N$ & d & $\begin{array}{c}\text { CORRECTED } \\
\text { SD }\end{array}$ & $\begin{array}{c}\text { \% VARIANCE } \\
\text { SAMPLING ERROR }\end{array}$ & $95 \% \mathrm{Cl}$ \\
\hline Affective & 7 & 195 & .80 & .24 & 74.27 & $.33,1.28$ \\
\hline Cognitive & 6 & 229 & 1.37 & .48 & 36.42 & $.41,2.33$ \\
\hline Subjective task-based skill & 6 & 152 & .88 & .35 & 59.01 & $.17,1.59$ \\
\hline Objective task-based skill & 13 & 504 & .76 & .40 & 41.50 & $-.03,1.56$ \\
\hline Teamwork skill & 9 & 333 & .64 & .33 & 51.91 & $-.01,1.30$ \\
\hline Overall ${ }^{\mathrm{a}}$ & 41 & 1,413 & .85 & .44 & 39.77 & $-.03,1.74$ \\
\hline
\end{tabular}

Note: $k=$ number of effect sizes; $N=$ total number of teams for studies combined; $d=$ mean sample-weighted effect size; corrected $S D=$ standard deviation of effect sizes corrected for sampling error; \% variance sampling error $=$ percentage of variance due to sampling error; $\mathrm{Cl}=$ confidence interval.

${ }^{a}$ Although we argue in this article that the five evaluation criteria focus on different aspects of the criterion space, we nonetheless present an overall effect size for the sake of completeness. 
team training did not have significantly stronger relationships with any particular type of effectiveness outcome.

\section{Moderator Analyses}

The small number of effect sizes and the relatively large magnitude of the percentage of variance accounted for by sampling error in the overall results and within each criterion category suggest that moderators of the relationship between team training and team effectiveness criteria are not likely to be present. However, one of the goals of the study was to examine potential moderators that are of theoretical interest to the team training literature. Therefore, moderator analyses were conducted to address the five moderator hypotheses posed.

Sample Type. Table 2 shows the meta-analytic results of the sample type moderator analysis for training administered to civilian and military samples. Hypothesis 3, predicting that sample type would moderate the relationship between team training and team effectiveness, was not supported. No significant differences in effect sizes were found across sample types for overall effectiveness $\left(d_{\text {military }}=1.05 ; d_{\text {civilian }}=.80\right)$ or for affective, subjective task-based skill, objective task-based skill, and teamwork skill outcomes.

\section{TABLE 2 META-ANALYSIS OF THE EFFECTS OF TEAM TRAINING ON TEAM TRAINING OUTCOMES: MILITARY VERSUS CIVILIAN SAMPLES}

\begin{tabular}{|c|c|c|c|c|c|c|}
\hline TEAM TRAINING OUTCOME & k & $N$ & d & $\begin{array}{c}\text { CORRECTED } \\
\text { SD }\end{array}$ & $\begin{array}{c}\text { \% VARIANCE } \\
\text { SAMPLING ERROR }\end{array}$ & $95 \% \mathrm{Cl}$ \\
\hline \multicolumn{7}{|l|}{ Military } \\
\hline Affective & 2 & 31 & 1.12 & 0 & 100 & $1.12,1.12$ \\
\hline Subjective task-based skill & 2 & 28 & 1.15 & 0 & 100 & $1.15,1.15$ \\
\hline Objective task-based skill & 2 & 88 & .85 & .19 & 73.60 & $.47,1.23$ \\
\hline Teamwork skill & 3 & 83 & .66 & 0 & 100 & $.66, .66$ \\
\hline Overall $^{a}$ & 10 & 270 & 1.05 & 1.02 & 57.23 & $.32,1.77$ \\
\hline \multicolumn{7}{|l|}{ Civilian } \\
\hline Affective & 4 & 144 & .84 & .24 & 69.05 & $.37,1.31$ \\
\hline Subjective task-based skill & 4 & 124 & .81 & .44 & 42.57 & $-.07,1.69$ \\
\hline Objective task-based skill & 11 & 416 & .74 & .43 & 38.67 & $-.11,1.60$ \\
\hline Teamwork skill & 6 & 250 & .64 & .43 & 35.78 & $-.22,1.49$ \\
\hline Overall ${ }^{\mathrm{a}}$ & 31 & 1,143 & .80 & .45 & 37.44 & $-.09,1.70$ \\
\hline
\end{tabular}

Note. $k=$ number of effect sizes; $N=$ total number of teams for studies combined; $d=$ mean sample-weighted effect size; corrected $S D=$ standard deviation of effect sizes corrected for sampling error; \% variance sampling error $=$ percentage of variance due to sampling error; $\mathrm{Cl}=$ confidence interval.

${ }^{a}$ Although we argue that the five evaluation criteria focus on different aspects of the criterion space, we nonetheless present an overall effect size for the sake of completeness. 
Research Setting. Table 3 shows the meta-analytic results of the research setting moderator analysis for training performed in lab and field settings. Hypothesis 4, predicting that research setting would moderate the relationship between team training and team effectiveness, was not supported. No significant differences in effect sizes were found across sample types for overall effectiveness $\left(d_{\text {laboratory }}=.87 ; d_{\text {field }}=.76\right)$ or for affective, objective task-based skill, and teamwork skill outcomes.

Team Status. Table 4 shows the meta-analytic results of the team status moderator analysis for training given to ad hoc and intact teams. Hypothesis 5 , predicting that team status would moderate the relationship between team training and team effectiveness, was not supported. No significant differences in effect sizes were found across sample types for overall effectiveness $\left(d_{\mathrm{ad} \text { hoc }}=.92 ; d_{\text {intact }}=.62\right.$ ) or for affective, subject task-based skill, objective task-based skill, and teamwork skill outcomes.

Evaluation Setting. Table 5 shows the meta-analytic results of the evaluation setting moderator analysis for effectiveness measurement in training and transfer environments. Hypothesis 6, predicting that evaluation setting would moderate the relationship between team training and team effectiveness, was partially supported. No significant differences in effect sizes were found across sample types for overall effectiveness $\left(d_{\text {training }}=.91\right.$; $\left.d_{\text {transfer }}=.68\right)$ or for affective, objective task-based skill, and teamwork skill outcomes. However, significant differences were found for cognitive

\section{TABLE 3 META-ANALYSIS OF THE EFFECTS OF TEAM TRAINING ON TEAM TRAINING OUTCOMES: FIELD VERSUS LAB SETTINGS}

\begin{tabular}{|c|c|c|c|c|c|c|}
\hline TEAM TRAINING OUTCOME & k & $N$ & $\boldsymbol{d}$ & $\begin{array}{c}\text { CORRECTED } \\
\text { SD }\end{array}$ & $\begin{array}{c}\text { \% VARIANCE } \\
\text { SAMPLING ERROR }\end{array}$ & $95 \% \mathrm{Cl}$ \\
\hline \multicolumn{7}{|l|}{ Field } \\
\hline Affective & 2 & 31 & 1.12 & 0 & 100 & $1.12,1.12$ \\
\hline Objective task-based skill & 3 & 105 & .62 & .38 & 45.35 & $-.15,1.39$ \\
\hline Teamwork skill & 3 & 110 & .77 & 0 & 100 & $.77, .77$ \\
\hline Overall ${ }^{\mathrm{a}}$ & 9 & 262 & .76 & 0 & 100 & $.76, .76$ \\
\hline \multicolumn{7}{|l|}{ Lab } \\
\hline Affective & 5 & 164 & .75 & .29 & 61.96 & $.17,1.32$ \\
\hline Objective task-based skill & 10 & 399 & .80 & .39 & 41.50 & $.01,1.59$ \\
\hline Teamwork skill & 6 & 223 & .58 & .45 & 36.19 & $-.31,1.48$ \\
\hline Overall $^{a}$ & 32 & 1,151 & .87 & .49 & 34.21 & $-.10,1.85$ \\
\hline
\end{tabular}

Note. $k=$ number of effect sizes; $N=$ total number of teams for studies combined; $d=$ mean sample-weighted effect size; corrected $S D=$ standard deviation of effect sizes corrected for sampling error; \% variance sampling error $=$ percent of variance due to sampling error; $\mathrm{Cl}=$ confidence interval.

${ }^{a}$ Although we argue that the five evaluation criteria focus on different aspects of the criterion space, we nonetheless present an overall effect size for the sake of completeness. 
TABLE 4 META-ANALYSIS OF THE EFFECTS OF TEAM TRAINING ON TEAM TRAINING OUTCOMES: INTACT VERSUS AD HOC TEAMS

\begin{tabular}{|c|c|c|c|c|c|c|}
\hline TEAM TRAINING OUTCOME & $k$ & $N$ & $d$ & $\begin{array}{l}\text { CORRECTED } \\
\text { SD }\end{array}$ & $\begin{array}{c}\% \text { VARIANCE } \\
\text { SAMPLING ERROR }\end{array}$ & $95 \% \mathrm{Cl}$ \\
\hline \multicolumn{7}{|l|}{ Intact } \\
\hline Affective & 2 & 62 & .60 & 0 & 100 & $.60, .60$ \\
\hline Subjective task-based skill & 2 & 36 & .63 & 0 & 100 & $.63, .63$ \\
\hline Objective task-based skill & 5 & 129 & .57 & .47 & 43.40 & $-.37,1.50$ \\
\hline Teamwork skill & 2 & 83 & .71 & 0 & 100 & $.71, .71$ \\
\hline Overall $^{\mathrm{a}}$ & 11 & 310 & .62 & .21 & 77.89 & $.20,1.04$ \\
\hline \multicolumn{7}{|l|}{ Ad Hoc } \\
\hline Affective & 5 & 133 & .90 & .24 & 74.19 & $.41,1.39$ \\
\hline Subjective task-based skill & 4 & 116 & .95 & .45 & 44.17 & $.06,1.85$ \\
\hline Objective task-based skill & 8 & 375 & .83 & .35 & 43.71 & $.14,1.52$ \\
\hline Teamwork skill & 7 & 250 & .62 & .42 & 40.85 & $-.21,1.45$ \\
\hline Overall $^{a}$ & 30 & 1,066 & .92 & .48 & 35.95 & $-.03,1.88$ \\
\hline
\end{tabular}

Note. $k=$ number of effect sizes; $N=$ total number of teams for studies combined; $d=$ mean sample-weighted effect size; corrected $S D=$ standard deviation of effect sizes corrected for sampling error; \% variance sampling error $=$ percentage of variance due to sampling error; $\mathrm{Cl}=$ confidence interval.

${ }^{a}$ Although we argue that the five evaluation criteria focus on different aspects of the criterion space, we nonetheless present an overall effect size for the sake of completeness.

outcomes $\left(d_{\text {training }}=1.21 ; d_{\text {transfer }}=2.40\right)$ given that the $95 \%$ confidence intervals for training (.48 to 1.94) and transfer (2.40 to 2.40) did not overlap. Thus, team training had stronger effects on cognitive outcomes for transfer applications than for training applications.

Study Design. Table 6 shows the meta-analytic results of the study design moderator analysis for experimental designs including between subjects, within subjects, and crossed within and between subjects. Hypothesis 7, predicting that evaluation setting would moderate the relationship between team training and team effectiveness, was partially supported. No significant differences in effect sizes were found across sample types for overall effectiveness $\left(d_{\text {between }}=.91 ; d_{\text {within }}=.73 ; d_{\text {crossed }}=.79\right)$ or for subjective task-based skill, objective task-based skill, and teamwork skill outcomes. However, significant differences were found for affective outcomes $\left(d_{\text {between }}=1.60 ; d_{\text {within }}=.58 ; d_{\text {crossed }}=.71\right)$ given that the $95 \%$ confidence interval for between-subjects designs (1.60 to 1.60) did not overlap with the intervals for within-subjects designs (.58 to .58 ) or crossed designs (.42 to .99). Thus, team training had stronger effects on affective outcomes when between-subjects designs were used rather than when within-subjects or crossed designs were used to measure effects. 
TABLE 5 META-ANALYSIS OF THE EFFECTS OF TEAM TRAINING ON TEAM TRAINING OUTCOMES: TRAINING VERSUS TRANSFER APPLICATIONS

\begin{tabular}{|c|c|c|c|c|c|c|}
\hline TEAM TRAINING OUTCOME & $k$ & $N$ & $d$ & $\begin{array}{c}\text { CORRECTED } \\
\text { SD }\end{array}$ & $\begin{array}{c}\text { \% VARIANCE } \\
\text { SAMPLING ERROR }\end{array}$ & $95 \% \mathrm{Cl}$ \\
\hline \multicolumn{7}{|l|}{ Training } \\
\hline Affective & 3 & 51 & .71 & .20 & 87.34 & $.31,1.11$ \\
\hline Cognitive & 4 & 198 & 1.21 & .37 & 41.88 & $.48,1.94$ \\
\hline Objective task-based skill & 7 & 358 & .57 & .42 & 33.28 & $.02,1.67$ \\
\hline Teamwork skill & 7 & 251 & .61 & .41 & 41.03 & $-.22,1.43$ \\
\hline Overall $^{\mathrm{a}}$ & 30 & 1,058 & .91 & .48 & 35.40 & $-.06,1.88$ \\
\hline \multicolumn{7}{|l|}{ Transfer } \\
\hline Affective & 4 & 144 & .84 & .24 & 69.05 & $.37,1.31$ \\
\hline Cognitive & 2 & 31 & 2.40 & 0 & 100 & $2.40,2.40$ \\
\hline Objective task-based skill & 6 & 146 & .55 & .26 & 72.47 & $.03,1.08$ \\
\hline Teamwork skill & 2 & 82 & .76 & 0 & 100 & $.76, .76$ \\
\hline Overalla & 11 & 355 & .68 & 21 & 74.76 & $.25,1.10$ \\
\hline
\end{tabular}

Note. $k=$ number of effect sizes; $N=$ total number of teams for studies combined; $d=$ mean sample-weighted effect size; corrected $S D=$ standard deviation of effect sizes corrected for sampling error; \% variance sampling error $=$ percent of variance due to sampling error; $\mathrm{Cl}=$ confidence interval.

${ }^{a}$ Although we argue that the five evaluation criteria focus on different aspects of the criterion space, we nonetheless present an overall effect size for the sake of completeness.

Other Methodological Factors. Although not specifically hypothesized in our study, we examined other potential methodological moderators of the relationship between team training and team effectiveness. These analyses revealed no significant differences in training outcomes for training content (team-oriented versus task-oriented), training designer (study author versus outside professional), or duration of training (short versus long). Thus, other methodological factors do not appear to moderate the relationship between team training and team effectiveness.

Determination of Publication Bias. The funnel plot for these data is shown in Figure 1. The graph indicates that the data from the study plot into a regular inverted funnel shape, indicating that the effect sizes for small studies span relatively evenly across the continuum of effect sizes and effect sizes for studies with a larger $N$ span a smaller section of the continuum (Light \& Pillemer, 1984). Therefore, the data in our study do not appear to be affected by publication bias.

\section{Discussion}

The purpose of the this study was to provide a quantitative summary of the existing published quantitative research on team training using 
TABLE 6 META-ANALYSIS OF THE EFFECTS OF TEAM TRAINING ON TEAM TRAINING OUTCOMES: BETWEEN, WITHIN, AND CROSSED RESEARCH DESIGNS

\begin{tabular}{|c|c|c|c|c|c|c|}
\hline $\begin{array}{l}\text { TEAM TRAINING } \\
\text { OUTCOME }\end{array}$ & $\boldsymbol{k}$ & $N$ & $d$ & $\begin{array}{c}\text { CORRECTED } \\
\text { SD }\end{array}$ & $\begin{array}{c}\text { \% VARIANCE } \\
\text { SAMPLING ERROR }\end{array}$ & $95 \% \mathrm{Cl}$ \\
\hline \multicolumn{7}{|l|}{ Between } \\
\hline Affective & 2 & 31 & 1.60 & 0 & 100 & $1.60,1.60$ \\
\hline Subjective task-based skill & 3 & 104 & .89 & .49 & 35.39 & $-.08,1.86$ \\
\hline Objective task-based skill & 9 & 257 & .72 & .46 & 41.93 & $-.20,1.65$ \\
\hline Teamwork skill & 6 & 223 & .58 & .45 & 36.19 & $-.31,1.48$ \\
\hline Overall $^{\mathrm{a}}$ & 26 & 844 & .91 & .56 & 31.11 & $-.20,2.03$ \\
\hline \multicolumn{7}{|l|}{ Within } \\
\hline Affective & 3 & 66 & .58 & 0 & 100 & $.58, .58$ \\
\hline Objective task-based skill & 4 & 247 & .80 & .31 & 42.07 & $.18,1.42$ \\
\hline Overall $^{a}$ & 8 & 333 & .73 & .24 & 64.29 & $.25,1.21$ \\
\hline \multicolumn{7}{|l|}{ Crossed } \\
\hline Affective & 2 & 98 & .71 & .14 & 81.00 & $.42, .99$ \\
\hline Subjective task-based skill & 2 & 28 & 1.15 & 0 & 100 & $1.15,1.15$ \\
\hline Teamwork skill & 3 & 110 & .77 & 0 & 100 & $.77, .77$ \\
\hline Overall $^{\mathrm{a}}$ & 7 & 236 & .79 & 0 & 100 & $.79, .79$ \\
\hline
\end{tabular}

Note. $k=$ number of effect sizes; $N=$ total number of teams for studies combined; $d=$ mean sample-weighted effect size; corrected $S D=$ standard deviation of effect sizes corrected for sampling error; \% variance sampling error = percentage of variance due to sampling error; $\mathrm{Cl}=$ confidence interval.

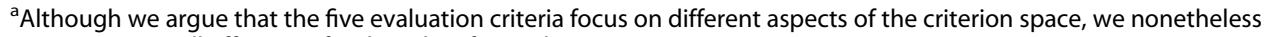
present an overall effect size for the sake of completeness.

meta-analysis to determine the impact of team training on team effectiveness. In this effort, we extended the Kraiger et al. (1993) model of multidimensional training outcomes to the team level of analysis. A literature search of published, quantitative studies yielded 41 observations of team training effects in 23 studies. These observations were categorized as affective outcomes, cognitive outcomes, subjective task-based skill outcomes, objective task-based skill outcomes, and teamwork skill outcomes.

In general, team training was highly associated with team effectiveness, with effect sizes ranging from .64 to 1.37. Moderator analyses were conducted for overall relationships and for relationships with each of the five outcome categories. (See Table 7 for a list of all moderator analysis results.) Although significant differences were found between training and transfer applications for cognitive outcomes and between study designs for affective outcomes, it should be noted that these findings were obtained with a relatively small number of effect sizes. Therefore, all results of the moderator analyses should be interpreted cautiously due to the small number of studies included in those analyses, the small number of teams in several of those 


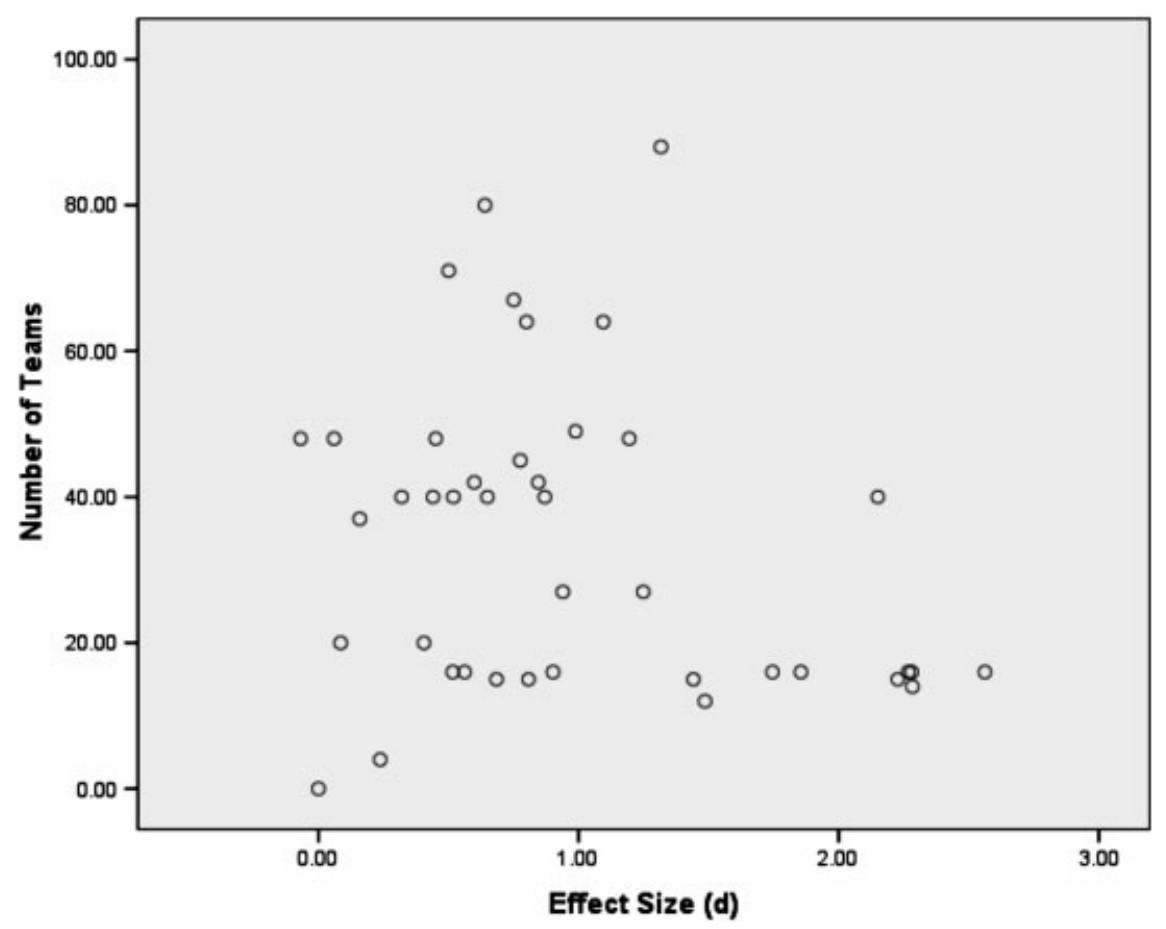

FIGURE 1. FUNNEL PLOT FOR DETECTING THE POSSIBILITY OF PUBLICATION BIAS

studies, and the large percentages of variance due to sampling error. With this in mind, the moderator analyses revealed that team training was similarly effective for samples of civilian and military teams. This lack of differential effects suggests that generalizing results across these two types of samples may be acceptable and meaningful. Moderator analyses also revealed that there were no differences in effectiveness across research setting, indicating that team training was similarly effective in lab and field studies. Moderator analyses also revealed there were no differences in effectiveness across team status, indicating that training may be equally effective for ad hoc and intact teams.

In contrast, the moderator analyses indicated differences in cognitive outcomes for evaluation setting but not for overall, affective, objective taskbased, or teamwork skills, suggesting that training is similarly effective in both proximal and distal application situations, except with cognitive outcomes. Analyses indicated that training had large positive effects on cognitive outcomes for training and transfer outcomes, but the effects were larger for transfer outcomes than for training outcomes. The lack of differences in the findings for most of the outcome types indicate that in this sample of studies, well-planned or well-executed efforts in training were similarly effective immediately after training and after a time lag and application to the transfer environment. Although the small number of effect sizes available for the moderator analyses must be considered in interpreting these results, the findings are encouraging because they indicate that although each type of training setting and situation provides its own unique challenges, high- 
TABLE 7 SUMMARY OF MODERATOR ANALYSIS RESULTS

\begin{tabular}{|c|c|c|c|c|c|c|c|c|c|c|c|c|}
\hline \multirow[t]{2}{*}{$\begin{array}{l}\text { TEAM } \\
\text { TRAINING } \\
\text { OUTCOME }\end{array}$} & \multirow[t]{2}{*}{ OVERALL } & \multicolumn{2}{|c|}{ SAMPLE TYPE } & \multicolumn{2}{|c|}{$\begin{array}{l}\text { RESEARCH } \\
\text { SETTING }\end{array}$} & \multicolumn{2}{|c|}{ TEAM STATUS } & \multicolumn{2}{|c|}{$\begin{array}{l}\text { EVALUATION } \\
\text { SETTING }\end{array}$} & \multicolumn{3}{|c|}{ STUDY DESIGN } \\
\hline & & Military & Civilian & Field & Lab & Intact & Ad hoc & Training & Transfer & Between & Within & Crossed \\
\hline Affective & .80 & 1.12 & .84 & 1.12 & & .60 & .90 & .71 & .84 & $1.60^{c}$ & $.58^{d}$ & $.71^{d}$ \\
\hline Cognitive & 1.37 & - & - & - & - & - & - & $1.21^{\mathrm{a}}$ & $2.40^{\mathrm{b}}$ & - & - & - \\
\hline Subjective skill & .88 & 1.15 & .81 & - & - & .63 & .95 & - & - & .89 & - & 1.15 \\
\hline Objective skill & .76 & .85 & .74 & .62 & .80 & .57 & .83 & .57 & .55 & .72 & .80 & - \\
\hline Teamwork skill & .64 & .66 & .64 & .77 & .58 & .71 & .62 & .61 & .76 & .58 & - & .77 \\
\hline Overall $^{\mathrm{a}}$ & .85 & 1.05 & .80 & .76 & .87 & .62 & .92 & .91 & .68 & .91 & .73 & .79 \\
\hline
\end{tabular}

Note. Different letters indicate significant differences in effect sizes within moderator analysis.

quality training applications can be applied in each situation to increase important team outcomes. The difference in results for cognitive outcomes may indicate that changes in cognitive outcomes that affect the way individuals think about their team or the team's task may become most effective when individuals have the opportunity to actively use those new cognitions (presumably cognitions similar to those of their team members) in the tasks they were meant to enhance. In addition, the moderator analyses indicated differences in affective outcomes for study design but not for overall, subjective task-based, objective task-based, or teamwork skills, suggesting that training is similarly effective in studies that used any type of appropriate design.

One potentially important moderator variable, training method, could not be examined due to prohi-

Because training programs
have discrete objectives, it
is not surprising that
methods across studies
were not similar enough to
allow for moderator
analyses.
bitively small sample sizes. A variety of training methods were represented in the literature reviewed for the study. For example, lecture was widely used as a training method, but was often used in tandem with other training methods such as group discussion, task practice sessions, or videos. Other training methods included task demonstration and practice, discussion meetings with a facilitator, and the use of training materials such as booklets, tapes, or CDs. Selection of appropriate training methods to deliver necessary training content and learning objectives is essential to designing an effective training program (Goldstein \& Ford, 2002). Therefore, because training programs have discrete objectives, it is not surprising that methods across studies were not similar enough to allow for moderator analyses.

\section{Suggestions for Team Training Research}

The meta-analytic results suggested four areas for improvement in team training research: conducting and assessing team training at the team level, 
reporting adequate statistical information, addressing deficiencies of key issues in the training field, and including moderator variables.

\section{Training at the Team Level}

Team training is training for teams that should be conducted and evaluated at the team level because the purpose of this training is to systematically build task- or teamwork-related skills to enhance team-level task performance. Although the prevalence of teams in organizations might suggest a similar prevalence of research on team training and its assessment, the literature indicates that relatively little quantitative training research addresses these two areas. Only 22 articles (23 studies) of the 56 articles initially believed to have a team training focus were included in this study because the remaining articles either did not focus on team-level training ( 7 studies) did not statistically measure a team criterion (10 studies measured individual criteria and 7 were nonempirical and did not measure any criteria), did not provide statistics necessary for inclusion in a meta-analysis (8 studies), or were case studies (2 studies).

In addition, a distinction should be drawn between team training, which includes systematic, formal, planned efforts to increase task-relevant task and teamwork skills, and team building, which is not systematic and focuses on problem solving and interpersonal issues rather than on specific task-related skills (Klein et al., 2009). A comparison of the results of the Klein et al. meta-analysis of the effects of team building on team outcomes with the results of this study indicates that overall and for most of the training outcome categories (affective, teamwork skill/ process, and skill-based outcomes/performance), there was little difference between the sizes of the effects of team training and team building. However, it is important to note that team training had a larger effect $(d=1.37 ; r=.57)$ than did team building $(r=.11)$ for cognitive outcomes. That finding, coupled with the paucity of team training research, indicates that more research should be done on team-level training that is evaluated using team-level criteria.

\section{Reporting Statistical Information}

Complete reporting of sufficient statistical information is necessary for inclusion of a study's results in a meta-analysis. Due to a lack of reported information, only 22 ( 23 studies) of the 31 possible articles for inclusion met the inclusion criteria because they did not provide the statistical information necessary to convert findings from individual studies into effect sizes that could be examined using the Hunter and Schmidt (1990) meta-analysis technique. To facilitate future meta-analyses of the team training literature, authors can report means, standard deviations, and reliability estimates for predictor and criterion variables. Also, it may be easier to identify and examine potential moderator variables if authors provide demographic information about participants (e.g., work experience, job level, age, expertise). In addition, the statistical accuracy of meta-analytic results will be increased to the extent they can include significant and nonsignificant values 
for relationships between predictor and criterion variables. This can be accomplished if authors report $F$-values for nonsignificant variables, $F$ values less than one, and nonsignificant test statistics. If effect sizes or correlations can be computed only for significant variables, the likelihood of finding larger effect sizes or correlations within a study or within a criterion category increases. For this study, the number of studies that did not report nonsignificant $F$-values was small, but the potential effect on the results of these analyses must be considered.

\section{Addressing Training Issues}

Future team training research should address transfer and evaluation. Few of the studies used in the analyses in this article assessed transfer from the training environment to the work environment. This was a function of the small number of field team training studies conducted. Although six of the seven field studies measured transfer outcomes, these represented only $26 \%$ of the team training studies and only $14.6 \%$ of the effect sizes used in this meta-analysis. Because transfer is a major goal of training, it would seem not only advantageous but also necessary to evaluate team training's transfer to the job in order to determine whether behavioral change occurred.

In addition to studying training transfer, attention should be directed toward the development of theoretical frameworks for evaluating team training. The researchers conducting many of the studies included in this analysis did not discuss levels or categories of training outcome criteria. Outcome measures were (rightly so) based on aspects of the tasks being trained. However, linking training outcomes to a framework such as the one presented by Kraiger et al. (1993) and extended in this article can highlight additional methods of training evaluation, particularly those based on cognitive research. For example, although many studies employed measures of objective task-based skill outcomes and teamwork skill outcomes, fewer studies employed measures of cognitive outcomes. Because a major focus of training is to present material so trainees readily learn it, it may be beneficial for researchers to use measures of trainee schemas, particularly to determine accuracy with respect to an expert schema and differences in pre- and posttraining schemas. These measures will enable researchers to assess whether knowledge was acquired. Team training literature can benefit from a systematic approach to training evaluation that encourages exploration of training effects from multiple viewpoints to capture the entire domain of training outcomes.

Another area that may improve the effectiveness of team training in research is careful attention to needs assessment, as Goldstein and Ford (2002) recommended. A needs assessment will provide researchers with the requisite information to determine if training is necessary and identify the areas where training can be helpful in reaching organizational goals. Training objectives and tasks must then be matched to those organizational needs. Team competencies necessary for performing a team task can also provide focus for training (Carroll \& McCrackin, 1998). In addition, Goldstein and Ford (2002) indicated that in order for training to transfer, training devel- 
opers must pay close attention to the behaviors that are ultimately expected in the transfer environment, the settings in which those behaviors should occur, the length of time new skills must be maintained, and factors that can motivate maintenance and further development of skills in the applied setting. Kozlowski and Salas (1997) also discussed the need for congruence between trained content areas and mindfulness of compilation and embeddedness of skills necessary for effective performance at different levels of the organization (particularly from the individual to the team level) in designing training that will easily lend itself to transfer into the organization. Given these recommendations, we considered coding the degree of match between training content and measured effectiveness criteria in each study. However, we found that for many of these studies, the degree of match between the content and criteria was difficult to determine, and coding proved subjective and therefore not appropriate for use in these analyses. Regardless of the training setting or situation, thorough needs assessment should be done to determine where training is necessary, which skills should be trained, and how best to train them to ensure transfer into unique applied environments.

\section{Moderator Variables}

Although the team training literature is growing, many moderator analyses could not be performed due to the small number of studies in which relevant variables were reported or assessed. It should be noted that we could evaluate only five moderator variables and that cognitive outcomes could be examined only for evaluation setting. Indications of differential effects were obtained only for cognitive and affective outcomes. Explanations for the moderator findings should be explored in future team training research.

In addition to these major issues, the studies found in the team training literature highlighted the sample size issue that afflicts much team research. Many team training studies presented a small sample of teams. Of those included in this meta-analysis, $56.5 \%$ of the studies (13 of 23 studies) had 40 teams or fewer, and $78.3 \%$ (18 of 23 studies) had fewer than 50 teams in the original study. Small sample sizes can limit the power of statistical findings, and research may benefit from increasing the number of teams participating in a given training episode. This item is likely to be more easily addressed with lab studies than field studies due to limitations in the field based on the availability of organizations and teams for participation in any one training intervention.

\section{Positive Insights About Team Training Research}

The meta-analysis results provided some positive insights about team training research. The results from the 23 studies examined indicated that team training is effective and can improve overall team effectiveness and each of the categories of team training outcomes. Also, evaluation setting and study design moderated the effect of team training on team outcomes, which has implications for team theory. The findings support the modifications made to the Kraiger et al. (1993) model and suggest that it should be used as a 
framework for evaluating training outcomes. Although the effect sizes found in our study for objective task-based $(d=.76 ; r=.36)$ and subjective taskbased $(d=.88 ; r=.40)$ skill outcomes were not significantly different, separation of task-based skill outcomes into categories by evaluation method still seems justified based on the widely different methods used to assess each type of outcome. In addition, the differences in effect sizes between teamwork skill outcomes $(d=.64 ; r=.30)$ and other team training outcomes suggest that the addition of the teamwork skill category to the framework is worthwhile for thorough team training evaluation.

Another positive aspect of team training research is that researchers typically used multiple measures of multiple criteria to assess team training outcomes, supporting the notion that team training outcomes are multidimensional. Indeed, team training affected all five types of outcomes used in these studies. It is particularly encouraging to note that several researchers utilized measures of teamwork skill outcomes because teamwork skills are essential for effective team performance and improving these skills should be a major focus of team training. We encourage future researchers to continue with this type of work. A review of this literature also reveals that researchers are increasingly incorporating advances in cognitive psychology (such as increased understanding of expertise and the acquisition of knowledge) when designing training programs and performance evaluation methods and for understanding team learning (e.g., Lee \& Johnson, 2008; Johnson \& O'Connor, 2008). This is particularly encouraging given that we found that cognitive outcomes had the largest average effect sizes from team training and that team training had a significantly larger positive effect on cognitive outcomes than on objective task-based skill outcomes or teamwork skill outcomes. Thus, team training research is adhering to the growing influence of cognitive psychology in the training and teams literature and to the call by Ford (1997) to include cognition in training research.

\section{Study Limitations}

As do all studies, this one had several limitations. First, several of the analyses included a small number of effect sizes for each category due to the small number of team training studies available. For this reason, we were also unable to examine several potential moderators, such as degree of interdependence of the teams, training content, training delivery method, reinforcement of training to the transfer environment, or climate for training. Given the limited information available in the primary studies, we were unable to correct for unreliability of the criteria or for range restriction. Also, we did not examine more finely grained predictors of team effectiveness (i.e., training components, delivery methods) because not only was there not enough literature available for those analyses but their relationships with training effectiveness have yet to be theoretically delineated. 


\section{Practical Implications}

The results of this study indicate that team training is effective overall and for each outcome category. Clearly the implication is that team training works, so organizations should continue to train their members who work on teams as whole teams and to foster improvements in affective, cognitive, and skill-based (subjective, objective, and teamwork) team-level outcomes. Although results indicate that team training is effective at different levels for different outcome categories, the bottom line is that team training is effective for all categories. This finding supports suggestions in the literature for continuing to train teams on teamwork skills (such as collaboration and support) and training general and specific teamwork skills (Brown, Eastham, \& Ku, 2006; Kolb \& Sandmeyer, 2008; Lee \& Johnson, 2008). Because the largest effect was found for cognitive outcomes, it seems that for practitioners in organizations, choosing team training as an intervention when they desire to enhance cognitive outcomes will be espe-

\section{The bottom line is that team training is effective for all categories.} cially beneficial. Furthermore, comparisons between cognitive results in the team training meta-analysis and the recent team-building meta-analysis (Klein et al., 2009) indicate that team training has a larger effect on cognitive outcomes than team building, suggesting that team training is a more appropriate intervention choice for modifying that type of effectiveness.

Also, results of the moderator analyses indicated very few areas where potential moderators influence the effectiveness of team training. These findings indicate that well-planned and well-implemented team training can be a positive phenomenon in organizations regardless of the characteristics of the teams, study design, or time of measurement. This quantitative evidence is encouraging in that it indicates that team training can be effective in a variety of situations and a variety of organizations. Of particular importance are the findings for training and transfer outcome assessment. Across training and transfer applications, team training was equally effective for all types of team effectiveness outcomes except cognitive outcomes, suggesting that appropriate team training can successfully address the important training transfer issue. However, results also indicate that more effective cognitive outcomes were found when they were measured in transfer environments than in training environments. This suggests that cognitive outcomes, for which team training was highly effective, can and do translate beyond the training environment into the work environment. Therefore, the major implication of this research is that cognition, which has received increasing attention as an important factor influencing team effectiveness, can be trained effectively in team environments. If researchers and practitioners can determine which type of outcomes they wish to improve in their team members, create training programs that specifically address those outcomes, and effectively implement them, they should observe positive changes in effectiveness outcomes in training and transfer. 


\section{References}

Asterisks denote studies included in the meta-analysis.

Aamodt, M. G. (2005). User's guide for Meta-Analyzer 5.2. Radford, VA: Radford University.

Aamodt, M. G. \& Custer, H. (2006). Who can best catch a liar? A meta-analysis of individual differences in detecting deception. The Forensic Examiner, 15, 6-11.

Allen, T. D., Eby, L. T., Poteet, M. L., Lentz, E., \& Lima, L. (2004). Career benefits associated with mentoring for protégés: A meta-analysis. Journal of Applied Psychology, 8, 127-136.

Arthur, W., Jr., Bennett, W., Jr., \& Huffcut, A. I. (2001). Conducting meta-analysis using SAS. Mahwah, NJ: Erlbaum.

Baldwin, T. T., \& Magjuka, R. J. (1997). Training as an organizational episode: Pretraining influences on trainee motivation. In J. K. Ford et al. (Eds.), Improving training effectiveness in work organizations (pp. 99-127). Mahwah, NJ: Erlbaum.

Barrick, M. R., Stewart, G. L., Neubert, M. J., \& Mount, M. K. (1998). Relating member ability and personality to work-team processes and team effectiveness. Journal of Applied Psychology, 83(3), 377-391.

Bettenhausen, K. L. (1991). Five years of group research: What we have learned and what needs to be addressed. Journal of Management, 17(2), 345-381.

Bommer, W. H., Johnson, J. L., Rich, G. A., Podsakoff, P. M., \& MacKenzie, S. B. (1995). On the interchangeability of objective and subjective measures of employee performance: A meta-analysis. Personnel Psychology, 48, 587-605.

*Bottger, P. C., \& Yetton, P. W. (1987). Improving group performance by training in individual problem solving. Journal of Applied Psychology, 72(4), 651-657.

Brown, L. A., Eastham, N. P., \& Ku, H. (2006). A performance evaluation of the collaborative efforts in an online group research project. Performance Improvement Quarterly, 19(3), 121-140.

*Brown, T. C. (2003). The effect of verbal self-guidance training on collective efficacy and team performance. Personnel Psychology, 56(4), 935-964.

*Buller, P. F. (1988). Long term performance effects of goal setting and team building interventions in an underground silver mine. Organization Development Journal, 6(2), 82-93.

*Buller, P. F., \& Bell, Jr., C. H. (1986). Effects of team building and goal setting on productivity: A field experiment. Academy of Management Journal, 29(2), 305-328.

Bushe, G. R., \& Coetzer, G. (1995). Appreciative inquiry as a team-development intervention: A controlled experiment. Journal of Applied Behavioral Science, 31(1), 13-30.

Campbell. J.P. (1971). Personnel training and development. Annual Review of Psychology, $22,565-602$.

Cannon-Bowers, J. A., \& Salas, E. (1997). A framework for developing team performance measures in training. In M. T. Brannick, E. Salas, \& C. Prince (Eds.), Team performance assessment and measurement (pp. 45-62). Mahwah, NJ: Erlbaum.

Cannon-Bowers, J. A., \& Salas, E. (1998). Team performance and training in complex environments: Recent findings from applied research. Current Directions in Psychological Science, 7, 83-87.

*Cannon-Bowers, J. A., Salas, E., Blickensderfer, E., \& Bowers, C. (1998). The impact of crosstraining and workload on team functioning: A replication and extension of initial findings. Human Factors, 40(1), 92-101.

Carnevale, A. P., \& Gainer, L. J. (1989). The learning enterprise. Washington, DC: American Society for Training and Development and Department of Labor.

Carroll, A., \& McCrackin, J. (1998). The competent use of competency-based strategies for selection and development. Performance Improvement Quarterly, 11(3), 45-63.

Colquitt, J. A., LePine, J. A., \& Noe, R. A. (2000). Toward an integrative theory of training motivation: A meta-analytic path analysis of 20 years of research. Journal of Applied Psychology, 85, 678-707. 
*Day, E. A., Arthur, W., Jr., Bell, S. T., Edwards, B. D., Bennett, W., Jr., Mendoza, J. L., et al. (2005). Ability-based pairing strategies in the team-based training of a complex skill: Does the intelligence of your training partner matter? Intelligence, 33, 39-65.

*Eden, D. (1985). Team development: A true field experiment at three levels of rigor. Journal of Applied Psychology, 70(1), 94-100.

*Eden, D. (1986). Team development: Quasi-experimental confirmation among combat companies. Group and Organization Studies, 11(3), 133-146.

*Ellis, A. P. J., Bell, B. S., Ployhart, R. E., Hollenbeck, J. R., \& Ilgen, D. (2005). An evaluation of generic teamwork skills training with action teams: Effects on cognitive and skillbased outcomes. Personnel Psychology, 58(3), 641-672.

*Entin, E., \& Serfaty, D. (1999). Adaptive team coordination. Human Factors, 41(2), 312-325.

Ford, F. J. (1997). Transfer of training: The criterion problem. Applied Psychology: An International Review, 46(4), 349-354.

Ford, J. K., Kozlowski, S. W. J., Kraiger, K., Salas, E., \& Teachout, M. S. (1997). Improving training effectiveness in work organizations. Mahwah, NJ: Erlbaum.

Ford, J. K., Quiñones, M. A., Sego, D. J., \& Sorra, J. S. (1992). Factors affecting the opportunity to perform trained tasks on the job. Personnel Psychology, 45, 511-527.

*Gibson, C. B. (2001). Me and us: Differential relationships among goal-setting training, efficacy, and effectiveness at the individual and team level. Journal of Organizational Behavior, 22(7), 789-808.

Goldstein, I. L., \& Ford, J. K. (2002). Training in organizations (4th ed.). Belmont, CA: Wadsworth.

Hackman, J. R. (1987). The design of work teams. In J. W. Lorsch (Ed.), Handbook of organizational behavior (pp. 315-342). Upper Saddle River, NJ: Prentice-Hill.

Hunter, J. E., \& Schmidt, F. L. (1990). Methods of meta-analysis: Correcting error and bias in research findings. Thousand Oaks, CA: Sage.

Hunter, J. E., \& Schmidt, F. L. (2004). Methods of meta-analysis: Correcting error and bias in research findings. Thousand Oaks, CA: Sage.

*Ibbetson, A., \& Newell, S. (1996). Winner takes all: An evaluation of adventure-based experiential training. Management Learning, 27(2), 163-185.

Ilgen, D. R. (1999). Teams embedded in organizations: Some implications. American Psychologist, 54, 129-138.

Johnson, T. E., \& O'Connor, D. (2008). Measuring team shared understanding using the analysis-constructed shared mental model methodology. Performance Improvement Quarterly, 21(3), 113-134.

*Kaiser, A., Hahlweg, K., Fehm, W. G., \& Groth, T. (1998). The efficacy of a compact psychoeducational group training program for married couples. Journal of Consulting and Clinical Psychology, 66(5), 753-760.

Klein, C., DiazGranados, D., Salas, E., Le, H., Burke, C. S., Lyons, R., et al. (2009). Does team building work? Small Group Research, 40(2), 181-222.

Kolb, J., \& Sandmeyer, L. E. (2008). Supporting project teams: A framework used in a university-community collaborative initiative. Performance Improvement Quarterly, 21(1), 61-76.

Kozlowski, S. W. J., \& Salas, E. (1997). A multi level organizational systems approach for the implementation and transfer of training. In J. K. Ford, S. W. J. Kozlowski, K. Kraiger, E. Salas, \& M. S. Teachout (Eds.) Improving training effectiveness in work organizations (pp. 247-287). Mahwah, NJ: Erlbaum.

Kraiger, K., Ford, J. K., \& Salas, E. (1993). Application of cognitive, skill-based, and affective theories of learning outcomes to new methods of training evaluation. Journal of Applied Psychology, 78, 311-328.

Lee, M., \& Johnson, T. E. (2008). Understanding the effects of team cognition associated with complex engineering tasks: Dynamics of shared mental models, task-SMM, and team-SMM. Performance Improvement Quarterly, 21(3), 73-95. 
*Liang, D. W., Moreland, R., \& Argote, L. (1995). Group versus individual training and group performance: The mediating factor of transactive memory. Personality and Social Psychology Bulletin, 21(4), 384-393.

Light, R. J., \& Pillemer, D. B. (1984). Summing up: The science of reviewing research. Cambridge, MA: Harvard University Press.

*Marks, M. A., Sabella, M. J., Burke, C. S., \& Zaccaro, S. J. (2002). The impact of cross-training on team effectiveness. Journal of Applied Psychology, 87(1), 3-13.

Mullen, B., \& Copper, C. (1994). The relation between group cohesiveness and performance: An integration. Psychological Bulletin, 115(2), 210-227.

O'Connor, D. L., \& Yoon, S. W. (2008). Editorial: Special issue on improving team performance. Performance Improvement Quarterly, 21(3), 3-5.

Paradise, A. (2008). ASTD 2008 state of the industry report. Alexandria, VA: ASTD.

Paris, C. R., Salas, E., \& Cannon-Bowers, J. A. (2000). Teamwork in multi-person systems: A review and analysis. Ergonomics, 43(8), 1052-1075.

*Polley, R. B., \& Eid, J. (1990). Leadership training on the Bergen Fjord: A case study and evaluation. Group and Organization Studies, 15(2), 192-211.

*Prichard, J. S., Stratford, R. J., \& Bizo, L. A. (2006). Team-skills training enhances collaborative learning. Learning and Instruction, 16, 256-265.

*Rapp, T. L., \& Mathieu, J. E. (2007). Evaluating and individually self-administered generic teamwork skills training program across time and levels. Small Group Research, 38(4), 532-555.

Rouillier, J. Z., \& Goldstein, I. L. (1993). The relationship between organizational transfer climate and positive transfer of training. Human Resource Development Quarterly, 4, 377-390.

Salas, E., Dickinson, T. L., Converse, S. A., \& Tannenbaum, S. I. (1992). Toward an understanding of team performance and training. In R. W. Sweezy \& E. Salas (Eds.), Teams: Their training and performance (pp. 3-29). Norwood, NJ: Ablex.

Salas, E., Rozell, D., Mullen, B., \& Driskell, J. E. (1999). The effect of team building on performance. Small Group Research, 30(3), 309-329.

Spector, D. E., \& Levine, E. L. (1987). Meta-analysis for integrating study outcomes: A Monte Carlo study of its susceptibility to type I and type II errors. Journal of Applied Psychology, 72, 3-9.

Stout, R. J., Salas, E., \& Fowlkes, J. E. (1997). Enhancing teamwork in complex environments though team training. Journal of Group Psychotherapy, Psychodrama, and Sociometry, 49(4), 163-187.

Sundstrom, E., DeMeuse, K. P., \& Futrell, D. (1990). Work teams: Applications and effectiveness. American Psychologist, 45, 120-133.

Tannenbaum, S. I., Beard, R. L., \& Salas, E. (1992). Team building and its influence on team effectiveness: An examination of conceptual and empirical developments. In K. Kelley (Ed.), Issues, theory, and research in industrial/organizational psychology (pp. 117-153). Amsterdam: North-Holland.

Tannenbaum, S. I., \& Yukl, G. (1992). Training and development in work organizations. Annual Review of Psychology, 43, 399-441.

*Volpe, C. E., Cannon-Bowers, J. A., Salas, E., \& Spector, P. E. (1996). The impact of crosstraining on team functioning: An empirical investigation. Human Factors, 38(1), $87-100$.

Wang, Z. M. (1994). Group attributional training as an effective approach to human resource development under team work systems. Ergonomics, 37(7), 1137-1144.

Zaccaro, S. J., \& McCoy, M. C. (1988). The effects of task and interpersonal cohesiveness on performance of a disjunctive group task. Journal of Applied Social Psychology, 18(10), 837-851. 


\section{Related Readings}

Asterisks denote studies included in the meta-analysis.

*Brannick, M. T., Prince, C., \& Salas, E. (2005). Can PC-based systems enhance teamwork in the cockpit? International Journal of Aviation Psychology, 15(2), 173-187.

*Pritchard, J. S. \& Ashleigh, M. J. (2007). The effects of team-skills training on transactive memory and performance. Small Group Research, 38, 696-726.

*Stone, N. J., \& Posey, M. (2008). Understanding coordination in computer-mediated versus face-to-face groups Computers in Human Behavior, 24, 827-851.

\section{LISA A. DELISE}

Lisa A. Delise is a doctoral candidate in the industrial/organizational psychology program at the University of Tennessee, Knoxville. Her research interests include cognition and processes in teams and sociocognitive leadership.E-mail: ldelise@utk.edu

\section{ALLEN GORMAN}

C. Allen Gorman, $\mathrm{PhD}$, is an assistant professor in the industrial/ organizational psychology program at Radford University. His research interests include performance measurement, training, and leadership. E-mail: cagorman@radford.edu

\section{ABBY M. BROOKS}

Abby M. Brooks, $\mathrm{PhD}$, is an assistant professor of communication studies at Georgia Southern University. Her research interests include small groups, organizational and interpersonal communication, leadership, and motivation.E-mail: abrooks@georgiasouthern.edu

\section{JOAN R. RENTSCH}

Joan R. Rentsch, professor of management at the University of Tennessee, Knoxville, earned her $\mathrm{PhD}$ in industrial/organizational psychology from the University of Maryland. Her research interests include cognition in teams, multicultural perspective-taking, and workplace absence. E-mail: jrentsch@utk.edu

\section{DEBRA STEELE-JOHNSON}

Debra Steele-Johnson received her $\mathrm{PhD}$ in industrial/organizational psychology from the University of Minnesota. She is currently at Wright State University. Her research interests include workplace training and motivation.E-mail: Debra.steele-johnson@wright.edu 